\title{
Correlation between left ventricular diastolic dysfunction and dyslipidaemia in asymptomatic patients with new-onset type 2 diabetes mellitus
}

\author{
K. M. Hassan Ayman ${ }^{1}$, A. Abdallah Mahmoud ${ }^{1}$, A. Abdel-Mageed Eman ${ }^{1 *}$, Sayed Marwa' ${ }^{1}$, M. Soliman Mona ${ }^{2}$ and \\ T. Kishk Yehia ${ }^{1}$
}

\begin{abstract}
Background: Poor glycaemic control is associated with a greater risk of development of heart failure in diabetic patients. We aimed to study the prevalence of left ventricular (LV) systolic and diastolic dysfunction in asymptomatic patients with new-onset type $2 \mathrm{DM}$. We conducted a cross-sectional study including patients with newly diagnosed (within 1 year) type $2 \mathrm{DM}$; all patients were between the ages of 30 and 60 years, normotensive and clinically asymptomatic and attended the outpatient clinic of the endocrinology unit at a university hospital between March 2016 and June 2017. Demographic characteristics, clinical risk factors and waist-hip ratio (WHR) were assessed. Blood samples for laboratory analysis were obtained. Detailed echocardiography was performed to evaluate systolic and diastolic function.
\end{abstract}

Results: A total of 100 patients were included. Sixty-one percent had diastolic dysfunction with preserved ejection fraction. Left ventricular diastolic dysfunction (LVDD) was more prevalent in diabetic patients with $\mathrm{HbA1c} \geq 8.1$ (75\%) Patients with LVDD had significant dyslipidaemia in comparison to those without LVDD. Multivariate logistic regression analysis showed that WHR and HbA1c levels are the only predictors of impaired diastolic function in patients with new-onset DM. Kaplan-Meier survival curves showed a significant correlation between the incidence of diastolic dysfunction and the duration of DM, with higher incidence with HbA1c $\geq 8.1$.

Conclusions: Diastolic dysfunction is highly prevalent in patients with newly diagnosed DM and is positively correlated with HbA1c level, obesity, dyslipidaemia and the duration of diabetes.

\section{Background}

Diabetes mellitus (DM) is a chronic health problem that has high morbidity and is rapidly spreading. It is estimated that by the year 2045, patients with DM will compromise approximately $9.9 \%$ of the total world population [1]. Owing to the high prevalence of obesity and sedentary lifestyle, type II diabetes (T2DM) is diagnosed in approximately $90 \%$ of diabetes cases [1].

\footnotetext{
* Correspondence: emoamr43@yahoo.com

'Department of Cardiovascular Medicine, Faculty of Medicine, Assiut University Hospitals, Asyut, Egypt

Full list of author information is available at the end of the article
}

In 2017, approximately 8 million adult patients suffered from DM (15\% of the adult population) in Egypt [2]. It is predicted that this number will reach 13.1 million by 2035. In Egypt, it is estimated that $43 \%$ of the diabetic population is undiagnosed [2].

T2DM is a metabolic disorder characterized by hyperglycaemia and insulin resistance which contribute to different cardiovascular risk factors, such as dyslipidaemia, hypertension and obesity [3, 4]. T2DM is also associated with abnormally high levels of inflammatory mediators and cytokines [5]. and has renal and vascular 
complications [6-8]. Together, these factors increase the cardiovascular risks in diabetic patients [9-12].

Diabetic cardiomyopathy (DCM) is a major cardiac complication in diabetic patients [12]. Recently, it was defined as myocardial dysfunction in a diabetic patient with the absence of any other possible cause for heart failure [11, 12].

Different theories suggest that hyperglycaemia has a role in the development of myocardial dysfunction in diabetic patients [7-14]. The different synchronized pathological processes lead to myocardial fibrosis, which is considered the main cause of diastolic and systolic dysfunctions in the diabetic heart [15].

Many investigators consider left ventricular diastolic dysfunction (LVDD) the first manifestation of cardiac remodelling in DM [16]. DM and HF affect each other in a bidirectional manner in the form of cause and outcome [12]. Nineteen percent of patients with heart failure are reported to have T2DM, and the presence of T2DM increases the risk of HF 2- to 8fold [17].

One of the serological markers indicated for periodic glycaemic control is haemoglobin A1c (HbA1c) a serological marker [18]. A $1 \%$ increase level of HbA1c is associated with an $8 \%$ increased risk of HF, independently of other cardiovascular (CV) risks [19]. Furthermore, HF worsens the quality of life and influences the therapeutic effect of hypoglycaemic agents [20].

Accordingly, it is highly recommended to perform early detection and management of myocardial dysfunction in the diabetic population before the development of overt HF.

In our study, we investigated the incidence and stage of LV diastolic dysfunction and dyslipidaemia in asymptomatic recently diagnosed T2DM patients.

\section{Methods}

\section{Patient selection}

Patients with new-onset diabetes mellitus were included if they met the following criteria: (1) age between 30 and 60 years, (2) diagnosed with T2DM within 1 year, (3) normotensive, (4) no symptoms of heart failure. The exclusion criteria were patients with valvular or ischaemic heart disease, hypertension (blood pressure > 130/80 $\mathrm{mmHg}$ ), atrial fibrillation, heart failure (congestive heart failure or heart failure with preserved ejection fraction), cardiomyopathy, renal failure, chronic pulmonary disease, thyroid dysfunction, severe anaemia, haemoglobinopathies, taking any drug that could affect left ventricular function or poor transthoracic echo window.

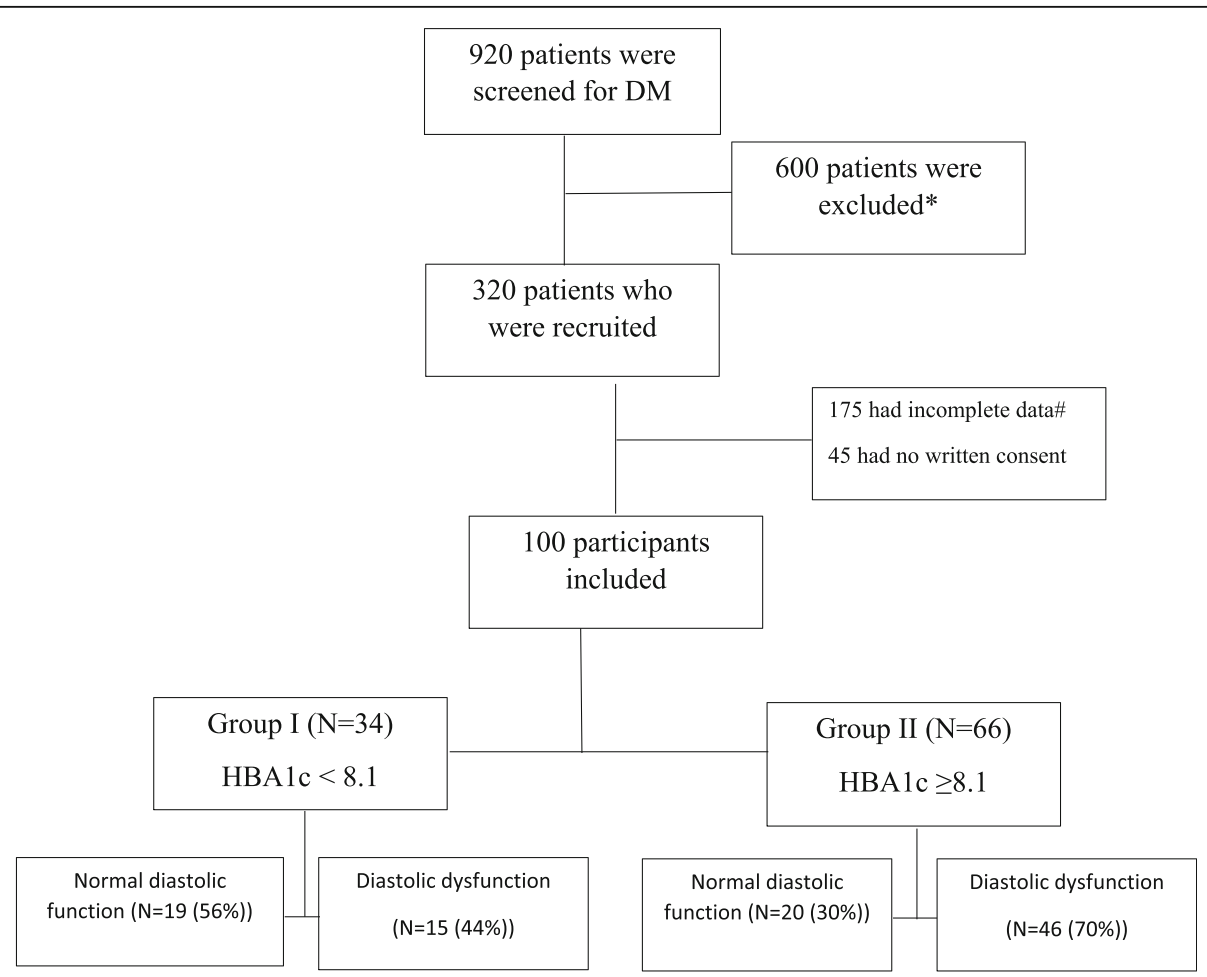

Fig. 1 Flowchart illustrating the presence of diastolic function in the study group according to glycated HbA1c. DM, diabetes mellitus. *Patient exclusion criteria are mentioned in details in the manuscript. \#Incomplete ECHO data due to bad window or unclear documentation and lack of complete laboratory results were excluded 


\section{Study design}

This study employed a cross-sectional design. Between March 2016 and June 2017, 920 patients were screened for DM in a dedicated outpatient clinic at our university hospitals. A total of 600 patients were excluded based on our exclusion criteria. Of the 320 patients who were recruited to the study, 175 had incomplete echocardiographic or laboratory data, and 45 had no written consent. These 220 patients were excluded, leaving 100 participants for this analysis.

Patients were classified according to their HbA1c level into two groups: group I with $\mathrm{HbA1c}<8.1$, and group II with $\mathrm{HbA1c} \geq 8.1$. Additionally, we reclassified the study group into two additional subgroups according to the presence or absence of LVDD (Fig. 1).

Table 1 Demographic, clinical and laboratory characteristics of the study group classified according to glycated HbA1c level

\begin{tabular}{|c|c|c|c|c|}
\hline Parameter & Study group $N=(100)$ & Group I $N=(34)$ & Group II $N=(66)$ & $P$ value \\
\hline Age (years) & $50 \pm 6$ & $50 \pm 6$ & $51 \pm 5$ & 0.9 \\
\hline Sex (male) & $53(53 \%)$ & $18(50 \%)$ & $35(55 \%)$ & 0.9 \\
\hline \multicolumn{5}{|l|}{ Smoking } \\
\hline Smokers & $42(42 \%)$ & $11(32 \%)$ & $31(47 \%)$ & \multirow[t]{3}{*}{0.3} \\
\hline Non-smokers & $56(56 \%)$ & $22(65 \%)$ & $34(51 \%)$ & \\
\hline Ex-smokers & $2(2 \%)$ & $1(3 \%)$ & $1(2 \%)$ & \\
\hline Duration of DM (months) ${ }^{a}$ & $7 \pm 4$ & $4.8 \pm 3$ & $5.1 \pm 4$ & 0.7 \\
\hline \multicolumn{5}{|l|}{ Treatment } \\
\hline Insulin & $34(34 \%)$ & $12(35 \%)$ & $22(33 \%)$ & \multirow[t]{3}{*}{0.1} \\
\hline $\mathrm{OHD}$ & $64(64 \%)$ & $20(59 \%)$ & $44(67 \%)$ & \\
\hline Insulin + OHD & $2(2 \%)$ & $2(6 \%)$ & $0(0 \%)$ & \\
\hline Weight (kg) & $89 \pm 12$ & $88 \pm 13$ & $90 \pm 11$ & 0.4 \\
\hline Height (cm) & $175 \pm 9$ & $173 \pm 9$ & $176 \pm 8$ & 0.8 \\
\hline Body mass index $\left(\mathrm{kg} / \mathrm{m}^{2}\right)$ & $29 \pm 4$ & $29 \pm 3$ & $30 \pm 4$ & 0.9 \\
\hline \multicolumn{5}{|l|}{ Body mass index class } \\
\hline Normal & $6(6 \%)$ & $2(6 \%)$ & $4(6 \%)$ & \multirow[t]{5}{*}{0.8} \\
\hline Overweight & $57(57 \%)$ & $18(53 \%)$ & 39 (59\%) & \\
\hline Obese class I & 31 (31\%) & $11(32 \%)$ & $20(30 \%)$ & \\
\hline Obese class II & $5(5 \%)$ & $3(9 \%)$ & $2(3 \%)$ & \\
\hline Obese class III & $1(1 \%)$ & $0(0 \%)$ & $1(2 \%)$ & \\
\hline Pulse (bpm) & $83 \pm 10$ & $83 \pm 11$ & $82 \pm 5$ & 0.8 \\
\hline Waist circumference $(\mathrm{cm})$ & $104 \pm 16$ & $102 \pm 16$ & $105 \pm 16$ & 0.7 \\
\hline Waist-hip ratio & $0.9 \pm 0.08$ & $0.8 \pm 0.08$ & $0.9 \pm 0.07$ & 0.4 \\
\hline \multicolumn{5}{|l|}{ Waist-hip ratio } \\
\hline$<0.8$ & $34(34 \%)$ & $13(38 \%)$ & $21(32 \%)$ & \multirow[t]{2}{*}{0.5} \\
\hline$>0.8$ & $66(66 \%)$ & $21(62 \%)$ & $45(68 \%)$ & \\
\hline Urea (mmol/L) & $5.3 \pm 2$ & $5.3 \pm 2$ & $5.4 \pm 2$ & 0.4 \\
\hline Creatinine ( $\mu \mathrm{mol} / \mathrm{L})$ & $74 \pm 27$ & $76 \pm 32$ & $73 \pm 23$ & 0.5 \\
\hline eGFR (mL/min/1.73 m2) & $117 \pm 29$ & $120 \pm 30$ & $112 \pm 31$ & 0.7 \\
\hline S. albumin (g/dL) & $3.8 \pm 0.4$ & $3.8 \pm 0.5$ & $3.7 \pm 0.4$ & 0.9 \\
\hline Total cholesterol (mg/dL) & $194 \pm 37$ & $182 \pm 38$ & $201 \pm 35$ & 0.02 \\
\hline Triglycerides (mg/dL) & $200 \pm 56$ & $182 \pm 51$ & $210 \pm 57$ & 0.03 \\
\hline LDL (mg/dL) & $127 \pm 27$ & $120 \pm 23$ & $130 \pm 28$ & 0.08 \\
\hline $\mathrm{HDL}(\mathrm{mg} / \mathrm{dL})$ & $41 \pm 10$ & $45 \pm 9$ & $39 \pm 10$ & 0.001 \\
\hline
\end{tabular}

Obesity class: overweight 25.0-29.9, obese class I 30.0-34.9, obese class II 35.0-39.9, obese class III $\geq 40$

eGFR estimated glomerular filtration rate, FBG fasting blood glucose, 2 hPPBG 2-h post-prandial blood glucose, HbA1c glycated haemoglobin, HDL high-density lipoprotein, $L D L$ low-density lipoprotein

${ }^{\mathrm{a}}$ Duration since diagnosis of diabetes mellitus in months 


\section{Study population}

We enrolled 100 consecutive patients who fulfilled the selection criteria for this study. Demographic characteristics, medical history in order to exclude any associated CV risk factors and smoking status were assessed. Patients were diagnosed according to the American Diabetes Association (ADA) recommendations [21]. These criteria for type II diabetes include $\mathrm{FBS} \geq 126 \mathrm{mg} / \mathrm{dL}$ and 2 -h plasma glucose $\geq 200$ $\mathrm{mg} / \mathrm{dL}$ during an OGTT, RBS $\geq 200 \mathrm{mg} / \mathrm{dL}$ with symptoms (polyuria, polydipsia, polyphagia, weight loss) and HbA1c > 6.5\%. Height $(\mathrm{cm})$ and body weight $(\mathrm{kg})$ were measured to calculate body mass index (BMI, $\mathrm{kg} / \mathrm{m}^{2}$ ) and identify obesity class as follows: Underweight was considered a BMI $<18.5$, normal 18.5-24.9, overweight $25.0-29.9$, obese I $30.0-$ 34.9 , obese II 35.0-39.9, and extremely obese $\geq 40$ [22]. Waist circumference (WC) with cutoff for high WC was $>85 \mathrm{~cm}$ for females and $>90 \mathrm{~cm}$ for males, and waist-hip ratio (WHR) with cutoff for high WHR was 0.9 for males and 0.8 for females [22]. Blood pressure was measured using a mercury sphygmomanometer and was assessed according to the current ESC guidelines in which hypertension is defined as a systolic blood pressure $\geq 140 \mathrm{mmHg}$ and/or diastolic blood pressure $\geq 90 \mathrm{mmHg}$ [23]. ECG was performed on all patients to exclude evident ischaemia or any chronic arrhythmias affecting LV diastolic function.

The study's protocol was approved by the institutional review board of the faculty of Medicine in our university and complied with the tenets of the 1964 Declaration of Helsinki and its later amendments (no:17100535). Informed written consent was obtained from all participants.

\section{Laboratory analysis}

Blood samples were collected after a minimum of 8 to $14 \mathrm{~h}$ of overnight fasting to identify patients with dyslipidaemias, which is defined as the atherogenic lipid triad of the co-existence of elevated triglycerides (TG) $>150$ $\mathrm{mg} / \mathrm{dl}$, increased low-density lipoprotein (LDL-C) particles $>130 \mathrm{mg} / \mathrm{dl}$ and reduced high-density lipoproteincholesterol (HDL-C) $<40 \mathrm{mg} / \mathrm{dl}$ levels [24].

To assess glucose tolerance status, all participants without known T2DM underwent a $2 \mathrm{~h} 75 \mathrm{~g}$ oral glucose tolerance test, and the definition of type II DM was established according to 2016 ADA criteria [21].

Glycated haemoglobin (HbA1c) measurement The blood specimens were collected and stored at 2 to $8{ }^{\circ} \mathrm{C}$ in $\mathrm{K}$-ethylenediaminetetraacetic acid (K-EDTA) tubes using a Tosoh G8 HPLC analyser (Tosoh Corporation). The test was performed only after exclusion of anaemia. Patients who had levels $>6.5 \%$ were considered to have diabetes according to the American Diabetes Association [21].

\section{Echocardiography assessment and parameters}

Echocardiography was performed using a GE Vivid 5 (5$1 \mathrm{MHz}$ multi-frequency probe) machine according to the standard protocol. Pulsed-wave Doppler (PWD)-derived transmitral inflow velocities were measured in the apical 4-chamber view, with the PW Doppler sample volume (1-3 $\mathrm{mm}$ axial size) between mitral leaflet tips [25]. Cardiac chamber diameters and LV wall thickness were measured by $\mathrm{M}$-mode. The area-length method was used to calculate the left atrial (LA) volume which was indexed to body surface area to calculate LA volume index. LV ejection fraction measurement was measured

Table 2 Comparison between echocardiographic findings (systolic and diastolic functions) of the study group classified according to glycated $\mathrm{HbA1c}$

\begin{tabular}{|c|c|c|c|c|}
\hline Parameter & Study group $N=(100)$ & Group I $N=(34)$ & Group II $N=(66)$ & $P$ value \\
\hline Ejection fraction (\%) & $66 \pm 5$ & $66 \pm 4$ & $65 \pm 5$ & 0.4 \\
\hline Left atrium size $(\mathrm{cm})$ & $3.8 \pm 0.4$ & $3.7 \pm 0.4$ & $3.8 \pm 0.4$ & 0.7 \\
\hline Left atrium volume index (LAVI $\left.-\mathrm{ml} / \mathrm{m}^{2}\right)$ & $31 \pm 4$ & $29 \pm 3$ & $31 \pm 4$ & 0.05 \\
\hline E wave $(\mathrm{cm} / \mathrm{s})$ & $53 \pm 18$ & $56 \pm 16$ & $51 \pm 18$ & 0.2 \\
\hline E/A ratio & $1 \pm 0.3$ & $1.1 \pm 0.3$ & $0.98 \pm 0.3$ & 0.1 \\
\hline Deceleration time (ms) & $215 \pm 66$ & $205 \pm 47$ & $220 \pm 74$ & 0.3 \\
\hline Isovolumetric relaxation time (ms) & $90 \pm 28$ & $97 \pm 24$ & $86 \pm 30$ & 0.06 \\
\hline$E / e^{\prime}$ & $10.6 \pm 3$ & $9.8 \pm 2$ & $11 \pm 3$ & 0.02 \\
\hline \multicolumn{5}{|l|}{ Diastolic function } \\
\hline Normal & $39(39 \%)$ & 19 (56\%) & $20(30 \%)$ & \multirow[t]{4}{*}{0.03} \\
\hline DDG I & $47(47 \%)$ & $13(38 \%)$ & $34(52 \%)$ & \\
\hline DDG II & $14(14 \%)$ & $2(6 \%)$ & 12 (18\%) & \\
\hline DDG III & $0(0 \%)$ & $0(0 \%)$ & $0(0 \%)$ & \\
\hline
\end{tabular}

DDG diastolic dysfunction grade, DT deceleration time, EF ejection fraction, IVRT isovolumetric relaxation time, $L A$ left atrium, $L A V I$ left atrium volume index 
Table 3 Comparison between baseline and laboratory characteristics of the study group classified according to presence or absence of diastolic dysfunction

\begin{tabular}{|c|c|c|c|}
\hline Parameter & Diastolic dysfunction $(\mathrm{Y}) N=(61)$ & Normal diastolic function $(\mathrm{N}) N=(39)$ & $P$ value \\
\hline Age (years) & $50 \pm 6$ & $51 \pm 3$ & 0.3 \\
\hline Sex (male) & $33(54 \%)$ & $20(51 \%)$ & 0.7 \\
\hline \multicolumn{4}{|l|}{ Smoking } \\
\hline Smokers & $24(39 \%)$ & $18(42 \%)$ & \multirow[t]{3}{*}{0.4} \\
\hline Non-smokers & $35(58 \%)$ & $21(54 \%)$ & \\
\hline Ex-smokers & $2(3 \%)$ & $0(0 \%)$ & \\
\hline Duration of DM (months) & $5.3 \pm 3$ & $4.5 \pm 3$ & 0.2 \\
\hline \multicolumn{4}{|l|}{ Treatment } \\
\hline Insulin & $17(28 \%)$ & $17(44 \%)$ & \multirow[t]{3}{*}{0.2} \\
\hline OHD & $42(69 \%)$ & $22(56 \%)$ & \\
\hline Insulin and OHD & $2(3 \%)$ & $0(0 \%)$ & \\
\hline \multicolumn{4}{|l|}{ Oral treatment } \\
\hline Sulfonylureas & $14(23 \%)$ & $4(25 \%)$ & \multirow[t]{3}{*}{0.2} \\
\hline Biguanides & $28(46 \%)$ & $18(46 \%)$ & \\
\hline Oral + insulin & $2(3 \%)$ & $0(0 \%)$ & \\
\hline Weight (kg) & $91 \pm 14$ & $87 \pm 8$ & 0.1 \\
\hline Height (cm) & $176 \pm 9$ & $173 \pm 8$ & 0.1 \\
\hline BMI (kg/m2) & $30 \pm 4$ & $29 \pm 3$ & 0.5 \\
\hline \multicolumn{4}{|l|}{ BMI class } \\
\hline Normal & $5(8 \%)$ & $1(3 \%)$ & \multirow[t]{5}{*}{0.2} \\
\hline Overweight & $33(54 \%)$ & $24(61 \%)$ & \\
\hline Obese class I & $17(28 \%)$ & $14(36 \%)$ & \\
\hline Obese class II & $5(8 \%)$ & $0(0 \%)$ & \\
\hline Obese class III & $1(2 \%)$ & $0(0 \%)$ & \\
\hline Pulse (bpm) & $83 \pm 9$ & $81 \pm 10$ & 0.4 \\
\hline WC (cm) & $103 \pm 17$ & $106 \pm 13$ & 0.4 \\
\hline WHR & $0.9 \pm 0.06$ & $0.8 \pm 0.08$ & 0.000 \\
\hline \multicolumn{4}{|l|}{ WHR } \\
\hline$<0.8$ & $10(16 \%)$ & $24(62 \%)$ & \multirow[t]{2}{*}{0.000} \\
\hline$>0.8$ & $51(84 \%)$ & $15(38 \%)$ & \\
\hline HbA1c & $9.5 \pm 2$ & $8.5 \pm 2$ & 0.007 \\
\hline Urea $(\mathrm{mmol} / \mathrm{L})$ & $5.7 \pm 2$ & $4.9 \pm 1$ & 0.3 \\
\hline Creatinine $(\mu \mathrm{mol} / \mathrm{L})$ & $73 \pm 23$ & $75 \pm 32$ & 0.6 \\
\hline eGFR $\left(\mathrm{mL} / \mathrm{min} / 1.73 \mathrm{~m}^{2}\right)$ & $116 \pm 23$ & $117 \pm 23$ & 0.9 \\
\hline S. albumin (g/dL) & $3.7 \pm 0.4$ & $3.8 \pm 0.5$ & 0.9 \\
\hline Total cholesterol (mg/dL) & $204 \pm 33$ & $180 \pm 39$ & 0.002 \\
\hline Triglycerides (mg/dL) & $215 \pm 57$ & $176 \pm 46$ & 0.000 \\
\hline LDL (mg/dL) & $132 \pm 28$ & $118 \pm 23$ & 0.008 \\
\hline $\mathrm{HDL}(\mathrm{mg} / \mathrm{dL})$ & $40 \pm 11$ & $43 \pm 8$ & 0.08 \\
\hline High total cholesterol (mg/dL) & $37(60 \%)$ & $17(44 \%)$ & 0.1 \\
\hline High triglycerides (mg/dL) & $57(93 \%)$ & $26(66 \%)$ & 0.001 \\
\hline High LDL (mg/dL) & $33(54 \%)$ & $14(36 \%)$ & 0.07 \\
\hline Statin therapy & $42(69 \%)$ & $19(49 \%)$ & 0.09 \\
\hline Retinopathy & $8(13 \%)$ & $1(2 \%)$ & 0.07 \\
\hline Neuropathy & $10(16 \%)$ & $3(7 \%)$ & 0.2 \\
\hline
\end{tabular}

Obesity class: overweight 25.0-29.9, obese class | 30.0-34.9, obese class II 35.0-39.9, obese class III $\geq 40$

$D M$ diabetes mellitus, $O H D$ oral hypoglycaemic drugs, $B M I$ body mass index, WC waist circumference, WHR waist hip ratio, eGFR glomerular filtration rate, S.albumin serum albumin, $L D L$ low density lipoproteins, $H D L$ high density lipoproteins 
by the modified biplane Simpson's method [26]. Transmitral peak velocities, E/A ratio and early mitral flow deceleration time (DT) were obtained at the tips of the mitral valve leaflets in an apical 4-chamber view using PW Doppler. Tissue Doppler imaging of peak systolic (S) and peak early diastolic ( $\left.\mathrm{e}^{\prime}\right)$ velocities recorded at the septal side of the mitral annulus. The mitral E/e' ratio was subsequently calculated as an index of LV diastolic filling pressure.

LVDD detection was based on a reduction in the E/A ratio, reduction in septal TDI $S, e^{\prime}$ velocities, septal E/e' ratio and LA volume index. Accordingly, normal diastolic function was defined as an E/A ratio $>1$, average $\mathrm{E} / \mathrm{e}^{\prime}<14$, septal $\mathrm{e}^{\prime}>7 \mathrm{~cm} / \mathrm{s}$, lateral $\mathrm{e}^{\prime}>10 \mathrm{~cm} / \mathrm{s}$ and left atrium volume index (LAVI) $<34 \mathrm{ml} / \mathrm{m}^{2}$. Grade I DD was defined as E/A ratio $<0.8$ and $\mathrm{E}$ wave $<50 \mathrm{~cm} / \mathrm{s}$ or $\mathrm{E} / \mathrm{A}$ ratio $<0.8$ but $\mathrm{E}$ wave $>50 \mathrm{~cm} / \mathrm{s}$ or $\mathrm{E} / \mathrm{A}$ ratio $>0.8$ $<2$ with average E/e $\mathrm{e}^{\prime}<14$ and LAVI $<34 \mathrm{ml} / \mathrm{m}^{2}$. Grade II $\mathrm{DD}$ was defined as $\mathrm{E} / \mathrm{A}$ ratio $<0.8$ but $\mathrm{E}$ wave $>50$ $\mathrm{cm} / \mathrm{s}$ or E/A ratio $>0.8<2$ with average $\mathrm{E} / \mathrm{e}^{\prime}>14$ and LAVI $>34 \mathrm{ml} / \mathrm{m}^{2}$ or both. Grade III DD was defined as E/A ratio $>2$, average $\mathrm{E} / \mathrm{e}^{\prime}>14$, septal $\mathrm{e}^{\prime}<7 \mathrm{~cm} / \mathrm{s}$, lateral $\mathrm{e}^{\prime}<10 \mathrm{~cm} / \mathrm{s}$ and LAVI $>34 \mathrm{ml} / \mathrm{m}^{2}$ [25].

\section{Statistical analysis}

A sample size of 100 was obtained by the formula $n=4$ $\mathrm{pq} / \mathrm{d} 2$ with a $95 \%$ confidence level, $10 \%$ beta error and $5 \%$ alpha error. Categorical data were presented as counts and proportions (percentages) and compared by Pearson's chi-square analysis or Fischer's exact test if the expected cell count for a $2 \times 2$ table was $<5$. The normal distribution of continuous data was tested using the Kolmogorov-Smirnov test. Continuous and normally distributed data are presented as the mean \pm 1 standard deviation and were compared by a two-tailed unpaired $t$ test. Correlations were Spearman's correlation coefficient test. Univariable and multivariable binary logistic regression models were performed to characterize predictors of diastolic dysfunction. Multivariable regression was performed using only variables with a probability value $<0.05$ in the univariable regression analysis. Univariable regression analyses were performed using all clinical and laboratory indices. Kaplan-Meier survival curves were performed to assess the relation between diastolic dysfunction and duration since diagnosis of DM. All $p$ values were 2 -tailed, and statistical significance was defined if $p<0.05$. All analyses were performed with the SPSS version 24.0 statistical software (SPSS, Inc., Chicago, Illinois).

\section{Results}

This cross-sectional study involved 100 nonhypertensive, non-ischaemic patients who were newly diagnosed with T2DM within 1 year (mean duration since diagnosis of $\mathrm{DM}=7 \pm 4$ months). The study group showed no sex difference with a mean age of $50 \pm 6$ years old and $37 \%$ obesity. Sixty-six patients (66\%) had markedly elevated levels of HbA1c (group II). Patient demographics and clinical and laboratory data are presented in Table 1. All patients had normal systolic function, but 61 patients (61\%) had LVDD (Table 2).

Patients were classified into two groups according to HbA1c level: group I (HA1c < 8.1) and group II (HA1c $\geq 8.1$ ). The 8.1 cutoff point was chosen based on local experts' consensus agreement after an initial pilot study. The mean fasting blood glucose level was $9.3 \pm 4 \mathrm{mmol} /$ L, 2-h post-prandial blood glucose was $11.9 \pm 4 \mathrm{mmol} / \mathrm{L}$, and mean HbAlc was $9.1 \pm 2$. The grade of diastolic dysfunction was higher in group II than in group I (Fig. 1). No significant differences were found between the groups, except for dyslipidaemia, which was significantly higher in group II (Table 1).

Assessment of systolic function revealed no significant differences between the groups. However, differences in the $\mathrm{E} / \mathrm{e}^{\prime}$ ratio and LAVI were significant, with a higher degree of diastolic dysfunction in group II (Table 2).

Patients were reclassified into two groups according to the presence or absence of LVDD (Table 3). Patients with LVDD had higher levels of fasting blood glucose (11 $\pm 4 \mathrm{mmol}), 2$-h post-prandial glucose $(13 \pm 4 \mathrm{mmol})$, HbA1c $(9.5 \pm 2 \%)$, dyslipidaemia and higher WHR in comparison to those with preserved LV diastolic function (Table 3).

High total cholesterol levels were observed in 37 (60\%) of patients with diastolic dysfunction. Furthermore, 57 (93\%) patients had high triglycerides, and 33 (54\%) patients had high LDL levels (Table 3).

In patients with diastolic dysfunction, 28 (46\%) received biguinides, and $42(69 \%)$ patients received statin therapy, while in patients with normal diastolic function, 18 (46\%) received biguinides and 19 (49\%) patients received statin therapy (Table 3). Eight (13\%) patients with diastolic dysfunction had retinopathy, and 10 (16\%) had neuropathy (Table 3).

Univariable and multivariable logistic regression analysis was done for the outcome of diastolic dysfunction using baseline characteristic data (age, sex, BMI, WHR and duration of DM) and lipid profile (total cholesterol, triglycerides, LDL and HDL). It revealed that WHR (OR $=0.2, \mathrm{CI}=0.06-0.5, p=0.002)$ and HbA1c level $(\mathrm{OR}=$ $2.7, \mathrm{CI}=1.0-7.5, p=0.04)$ were the only predictors of impaired diastolic function (Table 4).

Using Spearman's correlation test, E/e' was positively correlated $(r=0.4, p<0.01)$ with the duration since diagnosis of DM (Fig. 2). Furthermore, the Kaplan-Meier survival curve analysis showed that diastolic dysfunction may occur early, just 2 months after diagnosis of T2DM. Additionally, the longer the duration of T2DM was, the 
Table 4 Univariable and multivariable logistic regression analysis for prediction of diastolic dysfunction

\begin{tabular}{|c|c|c|c|c|c|c|}
\hline \multirow[t]{2}{*}{ Parameter } & \multicolumn{3}{|c|}{ Univariate analysis } & \multicolumn{3}{|c|}{ Multivariate analysis } \\
\hline & $\overline{O R}$ & $95 \% \mathrm{Cl}$ & $P$ value & $\overline{O R}$ & $95 \% \mathrm{Cl}$ & $P$ value \\
\hline Sex & 1.1 & $0.5-2.5$ & 0.8 & & & \\
\hline Age (years) & 1.04 & $0.9-1.1$ & 0.2 & & & \\
\hline DM duration (months) & 0.7 & $0.4-1.3$ & 0.3 & & & \\
\hline BMI & 0.9 & $0.9-1.1$ & 0.5 & & & \\
\hline WHR & 8.2 & $3.2-21$ & 0.000 & 0.2 & $0.06-0.5$ & 0.002 \\
\hline $\mathrm{HbA1c}$ & 0.7 & $0.6-0.9$ & 0.009 & 2.7 & $1.0-7.5$ & 0.05 \\
\hline $\mathrm{TC}(\mathrm{mg} / \mathrm{dL})$ & 0.98 & $0.97-0.99$ & 0.003 & & & \\
\hline LDL (mg/dL) & 0.97 & $0.97-0.99$ & 0.01 & & & \\
\hline $\mathrm{TG}(\mathrm{mg} / \mathrm{dL})$ & 0.98 & $0.97-0.99$ & 0.09 & & & \\
\hline $\mathrm{HDL}(\mathrm{mg} / \mathrm{dL})$ & 1.04 & $0.9-1.1$ & 0.001 & & & \\
\hline
\end{tabular}

$B M I$ body mass index, $C l$ confidence interval, $D M$ diabetes mellitus, WHR waist-hip ratio, HbA1c glycated haemoglobin, $H D L$ high-density lipoprotein, $L D L$ lowdensity lipoprotein, OR odds ratio, TC total cholesterol, TG triglycerides

higher the trend towards incidence of LVDD with HbA1c $\geq 8.1$ ( $p=0.08)$ (Fig. 3).

\section{Discussion}

The main findings of the study are (1) subclinical LVDD present in $61 \%$ of asymptomatic patients with newly diagnosed T2DM (within 1 year). (2) This high burden of LVDD was clearly manifested in the uncontrolled group and correlated with a high level of HbA1c $(\geq 8.1)$, dyslipidaemia (high TC, TG and low HDL) and WHR (obesity index).

Regarding the prevalence of LVDD, our results meet the findings of previously published reports. Poirier et al. [27] found that LVDD was present in $60 \%$ (28 out of 46) of asymptomatic patients with T2DM aged 38-67 years. Patil et al. [28] reported that $54 \%$ of patients with T2DM had asymptomatic LVDD. In a study by Jain et al. [29] including 212 patients, 30\% were found to have LVDD. Because of the high prevalence of LVDD in T2DM, Mishra et al. [30] concluded that T2DM is a strong independent predictor of asymptomatic LVDD in the absence of other structural heart diseases.

Echocardiographic assessment of LVDD is highly affected by age, heart rate, changes in volume status and arterial blood pressure. These factors are challenging to control [25]. To exclude the effect of age on the LV filling pattern, we included only patients aged between 30 and 60 years old in our study. In addition, we included certain TDI parameters, which are recommended by recent guidelines [25] to overcome technical limitations related to traditional echocardiographic parameters and are better correlated with LV filling pressures.

In our study, we found that the $\mathrm{E} / \mathrm{e}^{\prime}$ ratio and LAVI (as parameters of diastolic function) were significantly higher in group II. This may be explained by insulin resistance [31] and subsequent hyperinsulinaemia which may stimulate prohypertrophic changes in the myocardium [32]. This in turn leads to increased diastolic LV stiffness and increased cardiomyocyte hypertrophy which are determinants for cardiomyocyte resting tension that are independent of pressure overload [33]. Furthermore, a study on hospitalized diabetic patients with symptomatic HF which included obtaining a left ventricular endomyocardial biopsy [33] reported that cardiomyocyte resting tension was more important for the progression of LVDD in diabetic patients with normal LV EF, as seen in our study.

We also noted a higher prevalence of LVDD with uncontrolled T2DM (group II). In this group, 52\% had grade I LVDD, and $18 \%$ had grade II LVDD. None of our patients had restrictive LV filling patterns. This finding could be explained by our strict criteria to include only patients diagnosed with diabetes within 1 year. Similarly, Agrawal et al. [34] observed that most of his patients with LVDD (73\%) had impaired LV relaxation, $16 \%$ had a pseudonormal filling pattern and no patient had a restrictive filling pattern. On the other hand, Seferovic-Mitrovic et al. [35] found LVDD in only $11 \%$ of his patients, and all of them had only impaired relaxation, which can be explained on the basis of different study designs. Long-standing hyperglycaemia affects diastolic LV stiffness by multiple direct and indirect mechanisms [32]. Furthermore, it is reported that a $1 \%$ increase in HbA1c level is associated with an increase in the risk of HF by $8 \%$ [36]. Jain et al. [37] reported that as HbA1c increased, LVDD deteriorated. They found that 8 out of 16 patients with $\mathrm{HbA1c}>9.5$ had grade III LVDD. On the other hand, only $34.3 \%$ of those with HbA1c of 6.5-7.5 had LVDD. Kumar et al. [38] stated that patients with $\mathrm{HbA} 1 \mathrm{c}>7.5 \%$ had a higher prevalence 


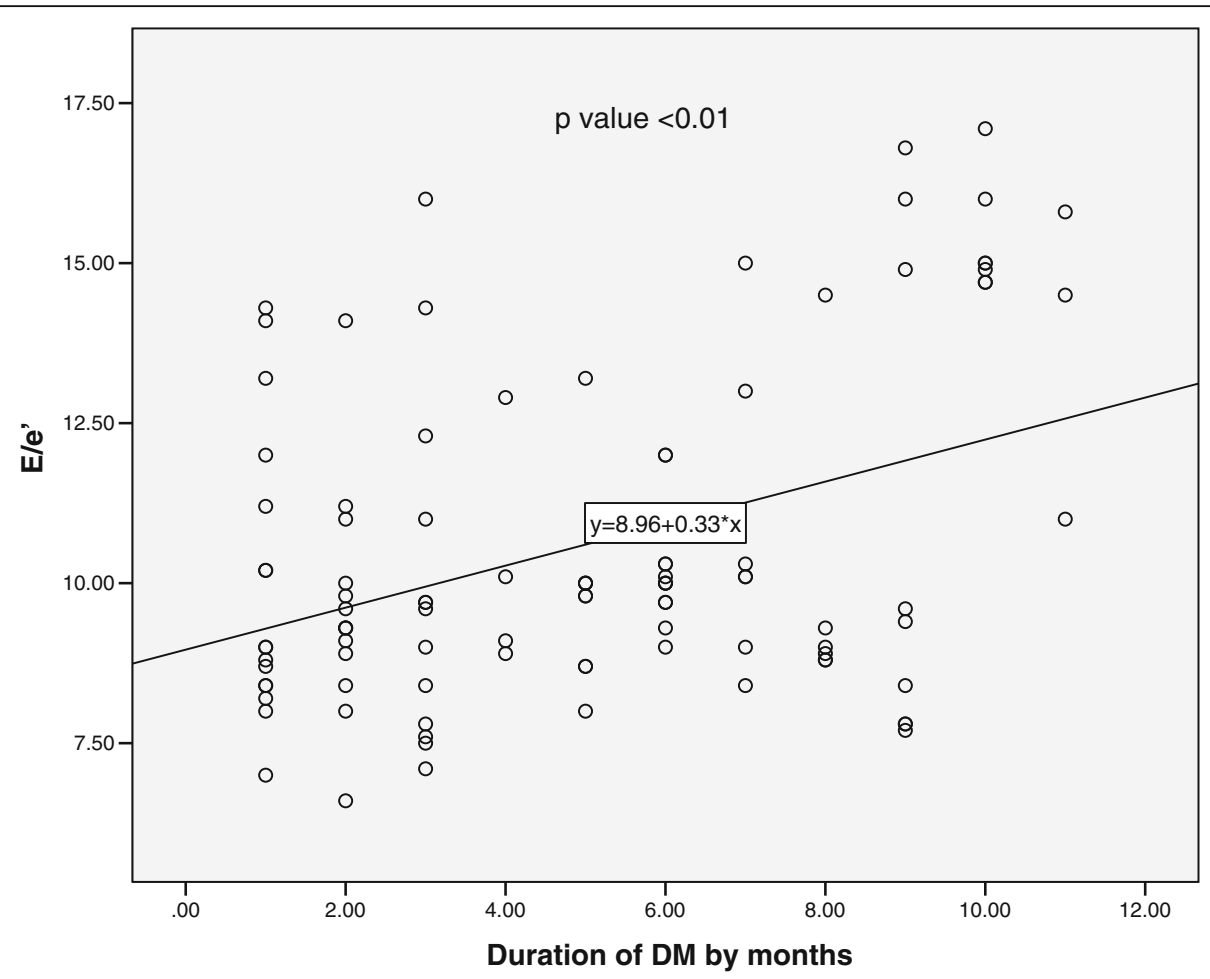

Fig. 2 Correlation between diastolic function and duration of diabetes mellitus

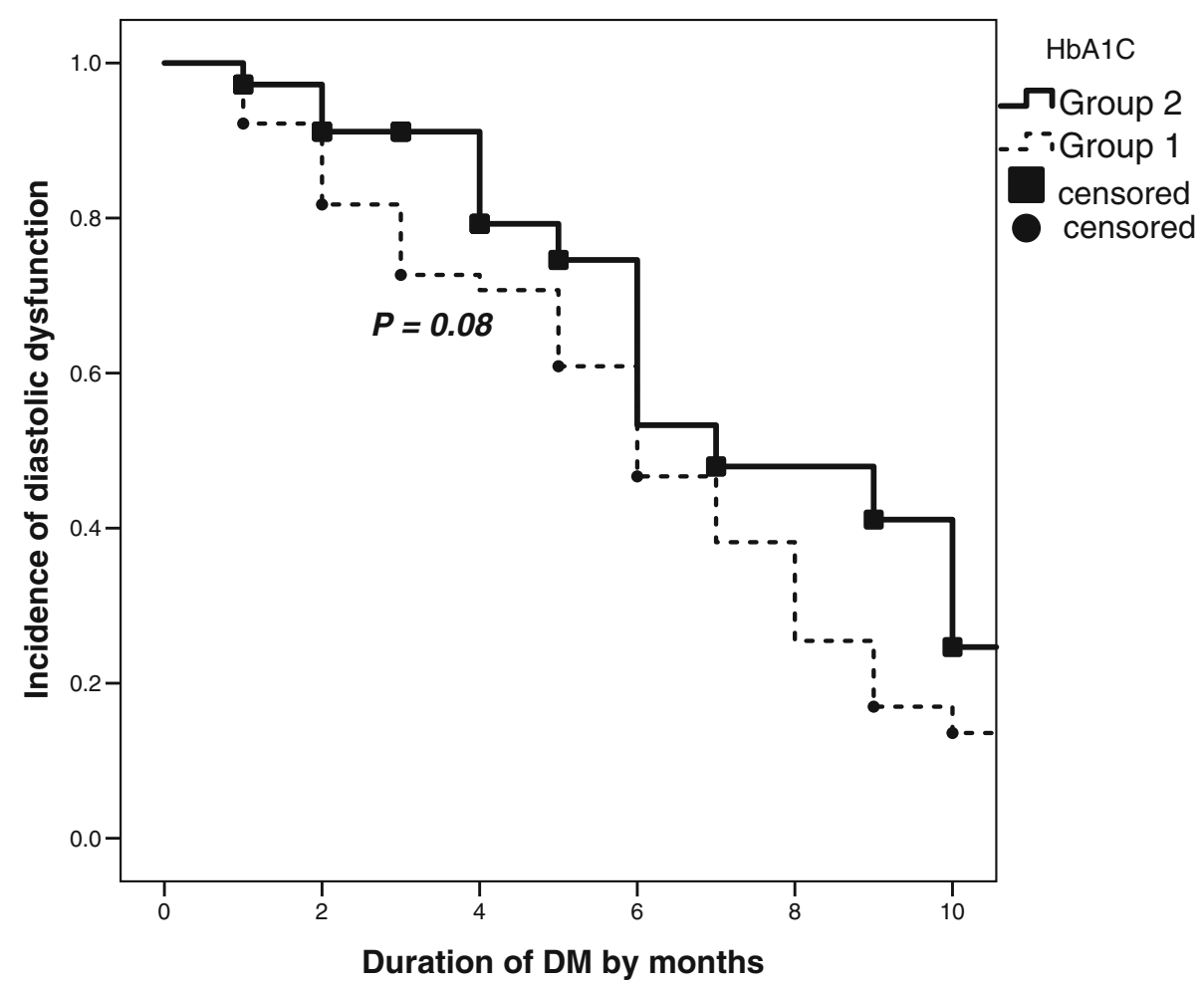

Fig. 3 Kaplan Meier survival curve showing time to diagnosis of diastolic dysfunction within 12 months of DM diagnosis 
of diastolic dysfunction compared to HbA1c $<7.5 \%$. Suresh et al. [39] found that patients with HbAlc $>8.1 \%$ had a higher prevalence of diastolic dysfunction compared to HbA1c < 8.1\%. Furthermore, LVDD was more prevalent in diabetic patients with HbA1c values greater than $8.1 \%$. In our study, we found that LVDD was more prevalent in diabetic patients with HbA1c $\geq 8.1$. Accordingly, early detection of LVDD at the time of DM diagnosis and competent control of hyperglycaemia could interfere with the progression to overt HF and might even improve the prognosis of such patients.

Among all echocardiographic Doppler parameters, E/e ' was a powerful predictor of myocardial infarction and stroke, comparable to HbA1c and even superior to global longitudinal strain and LVEF [40]. Therefore, performing diastolic stress testing using these novel Doppler techniques could be helpful for unmasking an advanced degree of diastolic dysfunction in diabetic patients with apparently normal diastolic function or with early-stage diastolic dysfunction. In our study, we found an intermediate correlation between septal $\mathrm{E} / \mathrm{e}^{\prime}$ and the duration of DM. We also observed that LVDD develops early in the course of the disease (2 months after the diagnosis). Furthermore, the longer the duration of the disease, the higher the LVDD grade. Our observations are in agreement with Patil et al. [28] who reported a strong correlation between LVDD and longer DM duration, HbA1c levels and obesity with the onset of DM for $>5$ years. Similarly, From et al. [41] observed that a duration of diabetes $>4$ years was independently associated with LVDD assessed by E/e' $>15$.

Regarding obesity as a confounder, overweight and obesity are proven to be associated with abnormal LV remodelling and subsequently abnormal high $\mathrm{E} / \mathrm{e}^{\prime}$ ratio $[21,27]$. In our study, only the WHR, as one of the obesity indices, was higher in the group with LVDD. In agreement with our study, Patil et al. [28] reported that out of 23 male and 13 female diabetic patients who had a high BMI, 16 males and 8 females had LVDD. According to Jain et al. [37], all patients with grade II or III LVDD had a BMI > 25. Similar to our findings, all patients with grade II DD had BMI $>25$.

In the present study, patients with LVDD had dyslipidaemia in comparison to those with normal LV diastolic function. In agreement with our findings, Cioffi et al. [42] reported that HbA1c and LDL are predictors of LVDD.

However, in a study with a population of 87 subjects, Schannwell et al. concluded that even young subjects with DM and normal EF suffered from diastolic dysfunction [43]. The present study observed that diastolic dysfunction was not related to age (patients $<30$ and $>60$ years were excluded), but was related to the duration of DM (e.g., the longer the duration was, the higher the incidence of LVDD).
Our current findings demonstrated a high prevalence of subclinical LVDD in asymptomatic early diagnosed T2DM patients. This high burden of LVDD was clearly manifested in the uncontrolled group and correlated with $\mathrm{HbA1c}$, poor cholesterol profile and obesity.

Limitations of our study include the following: (1) This cross-sectional study involved a relatively small number of patients in a single centre; however, our hospital is the only university hospital serving a region of 20 million people. (2) Lack of a control group and follow-up. Future studies with larger patient populations and a longitudinal cohort design including a control group are necessary to support our findings. (3) Although we excluded patients with clinical signs of coronary artery disease (CAD), a coronary angiogram was not performed to rule out $C A D$, which may lead to the inclusion of subclinical or undiagnosed CAD cases. (4) Detailed analysis of LV systolic and diastolic functions using new strain and strain rate techniques as well as diastolic stress testing may add important information in the future.

\section{Conclusion}

Diastolic dysfunction is highly prevalent in patients with newly diagnosed DM and seems to be positively correlated with HbA1c level, obesity, dyslipidaemia and the duration of diabetes.

\section{Abbreviations}

T2DM: Type 2 diabetes; DCM: Diabetic cardiomyopathy; HbA1c: Glycated haemoglobin; HF: Heart failure; LVDD: Left ventricular diastolic dysfunction; WHR: Waist-hip ratio

\section{Acknowledgements}

None

\section{Authors' contributions}

YK contributed to designing the study, defining the intellectual content, performing data analysis, manuscript preparation and review. MSo contributed to designing the study, defining the intellectual content, performing data analysis, manuscript preparation, editing and review. $\mathrm{AH}$ contributed to designing the study, defining the intellectual content, data acquisition, performing data analysis, manuscript preparation and review. MA contributed to designing the study, defining the intellectual content, data acquisition, performing data analysis, manuscript preparation and review. EAA was responsible for literature searching, data acquisition and statistical analysis, manuscript preparation and review. All authors (YK, MSo, MSa, EA, AK and MA) have read and approved the manuscript.

\section{Funding}

No funding was received for this study

Availability of data and materials

Data and material are available on request

\section{Ethics approval and consent to participate}

We received written informed consent for participation from the patients. The study's protocol was approved by the institutional review board of the faculty of Medicine in our university on 29 August 2016, and complied with the tenets of the 1964 Declaration of Helsinki and its later amendments. Ethical approval number 17101258. 


\section{Consent for publication}

We received informed consent for publication from all patients and study participants.

\section{Competing interests}

The authors have no competing interests

\section{Author details}

'Department of Cardiovascular Medicine, Faculty of Medicine, Assiut University Hospitals, Asyut, Egypt. ${ }^{2}$ Department of Internal Medicine, Faculty of Medicine, Assiut University Hospitals, Asyut, Egypt.

Received: 11 November 2020 Accepted: 14 January 2021

Published online: 16 February 2021

\section{References:}

1. Cho N, Shaw J, Karuranga S, Huang Y, da Rocha FJ, Ohlrogge A et al (2018) IDF Diabetes Atlas: global estimates of diabetes prevalence for 2017 and projections for 2045. Diabetes Res Clin Pract 138:271-281

2. Ogurtsova K, da Rocha FJ, Huang Y, Linnenkamp U, Guariguata L, Cho N et al (2017) IDF Diabetes Atlas: global estimates for the prevalence of diabetes for 2015 and 2040. Diabetes Res Clin Pract 128:40-50

3. Guo S-X, Yan Y-Z, Mu L-T, Niu Q, He J, Liu J-M et al (2015) Association of serum free fatty acids with hypertension and insulin resistance among rural uyghur adults in far Western China. Int J Environ Res Public Health 12(6): 6582-6590

4. Zhang T, Zhang H, Li S, Li Y, Liu Y, Fernandez C et al (2016) Impact of adiposity on incident hypertension is modified by insulin resistance in adults: Iongitudinal observation from the Bogalusa Heart Study. Hypertension. 67(1):56-62

5. Abate N, S Sallam H, Rizzo M, Nikolic D, Obradovic M, Bjelogrlic P et al (2014) Resistin: an inflammatory cytokine. Role in cardiovascular diseases, diabetes and the metabolic syndrome. Curr Pharm Des 20(31):4961-4969

6. Collaboration ABI (2008) Ankle brachial index combined with Framingham Risk Score to predict cardiovascular events and mortality: a meta-analysis. JAMA 300(2):197

7. Fox CS, Matsushita K, Woodward M, Bilo HJ, Chalmers J, Heerspink HJL et al (2012) Associations of kidney disease measures with mortality and endstage renal disease in individuals with and without diabetes: a metaanalysis. Lancet 380(9854):1662-1673

8. Goderis G, Van Pottelbergh G, Truyers C, Van Casteren V, De Clercq E, Van Den Broeke C et al (2013) Long-term evolution of renal function in patients with type 2 diabetes mellitus: a registry-based retrospective cohort study. BMJ Open 3(12):e004029

9. Pappachan JM, Varughese GI, Sriraman R, Arunagirinathan G (2013) Diabetic cardiomyopathy: pathophysiology, diagnostic evaluation and management. World J Diabetes 4(5):177

10. Fang ZY, Prins JB, Marwick TH (2004) Diabetic cardiomyopathy: evidence, mechanisms, and therapeutic implications. Endocr Rev 25(4):543-567

11. Aneja A, Tang WW, Bansilal S, Garcia MJ, Farkouh ME (2008) Diabetic cardiomyopathy: insights into pathogenesis, diagnostic challenges, and therapeutic options. Am J Med 121(9):748-757

12. Jia G, DeMarco VG, Sowers JR (2016) Insulin resistance and hyperinsulinaemia in diabetic cardiomyopathy. Nat Rev Endocrinol 12(3):144

13. Fowler MJ (2008) Microvascular and macrovascular complications of diabetes. Clin Diab 26(2):77-82

14. Chirinos JA, Segers P, Gillebert TC, et al (2013) Central pulse pressure and its hemodynamic determinants in middle-aged adults with impaired fasting glucose and diabetes: the Asklepios study. Diabetes Care 36(8):2359-2365 https://doi.org/10.2337/dc12-1463

15. Battiprolu PK, Hojayev B, Jiang N, Wang ZV, Luo X, Iglewski M et al (2012) Metabolic stress-induced activation of FoxO1 triggers diabetic cardiomyopathy in mice. J Clin Invest 122(3):1109-1118

16. Agarwal SK, Chambless LE, Ballantyne CM, Astor B, Bertoni AG, Chang PP et al (2012) Prediction of incident heart failure in general practice: the ARIC study. Circ Heart Fail 5(4):422

17. Wang TJ, Evans JC, Benjamin EJ, Levy D, LeRoy EC, Vasan RS (2003) Natural history of asymptomatic left ventricular systolic dysfunction in the community. Circulation. 108(8):977-982

18. van Melle JP, Bot M, De Jonge P, De Boer RA, van Veldhuisen DJ, Whooley MA (2010) Diabetes, glycemic control, and new-onset heart failure in patients with stable coronary artery disease: data from the heart and soul study. Diabetes Care 33(9):2084-2089

19. Galderisi M (2006) Diastolic dysfunction and diabetic cardiomyopathy: evaluation by Doppler echocardiography. J Am Coll Cardiol 48(8):1548-1551

20. Loncarevic B, Trifunovic D, Soldatovic I, Vujisic-Tesic B (2016) Silent diabetic cardiomyopathy in everyday practice: a clinical and echocardiographic study. BMC Cardiovasc Disord 16(1):242

21. Association AD (2017) Classification and diagnosis of diabetes. Diabetes Care 40(Supplement 1):S11-S24

22. Huxley R, Mendis S, Zheleznyakov E, Reddy S, Chan J (2010) Body mass index, waist circumference and waist: hip ratio as predictors of cardiovascular risk - a review of the literature. Eur J Clin Nutr 64(1):16-22

23. Williams B, Mancia G, Spiering W, Agabiti Rosei E, Azizi M, Burnier M et al (2018) 2018 ESC/ESH Guidelines for the management of arterial hypertension. Eur Heart J 39(33):3021-3104

24. Reiner Ž, Catapano AL, De Backer G, Graham I, Taskinen M-R, Wiklund O et al (2011) ESC/EAS Guidelines for the management of dyslipidaemias: the Task Force for the management of dyslipidaemias of the European Society of Cardiology (ESC) and the European Atherosclerosis Society (EAS). Eur Heart J 32(14):1769-1818

25. Naqueh SF, Smiseth OA, Appleton CP, Byrd BF, Dokainish H, Edvardsen T et al (2016) Recommendations for the evaluation of left ventricular diastolic function by echocardiography: an update from the American Society of Echocardiography and the European Association of Cardiovascular Imaging. J Am Soc Echocardiogr 29(4):277-314

26. Lang RM, Badano LP, Mor-Avi V, Afilalo J, Armstrong A, Ernande L et al (2015) Recommendations for cardiac chamber quantification by echocardiography in adults: an update from the American Society of Echocardiography and the European Association of Cardiovascular Imaging. J Am Soc Echocardiogr 28(1):1-39 e14

27. Poirier P, Bogaty P, Garneau C, Marois L, Dumesnil J-G (2001) Diastolic dysfunction in normotensive men with well-controlled type 2 diabetes: importance of maneuvers in echocardiographic screening for preclinical diabetic cardiomyopathy. Diabetes Care 24(1):5-10

28. Patil VC, Patil HV, Shah KB, Vasani JD, Shetty P (2011) Diastolic dysfunction in asymptomatic type 2 diabetes mellitus with normal systolic function. J Cardiovasc Dis Res 2(4):213-222

29. Jain K, Palange AA, Kakrani AL, Dhanorkar AS (2017) Left ventricular diastolic dysfunction in asymptomatic type 2 diabetes mellitus patients. Int J Res Med Sci 6(1):240-246

30. Mishra TK, Rath PK, Mohanty NK, Mishra SK (2008) Left ventricular systolic and diastolic dysfunction and their relationship with microvascular complications in normotensive, asymptomatic patients with type 2 diabetes mellitus. Indian Heart J 60(6):548-553

31. Hercil A, Devereux RB, Roman MJ, Paranicas M, O'Grady MJ, Lee ET et al (2002) Associations of insulin levels with left ventricular structure and function in American Indians: the strong heart study. Diabetes. 51(5):15431547

32. Poornima IG, Parikh P, Shannon RP (2006) Diabetic cardiomyopathy: the search for a unifying hypothesis. Circ Res 98(5):596-605

33. van Heerebeek L, Hamdani N, Handoko ML, Falcao-Pires I, Musters RJ, Kupreishvili K et al (2008) Diastolic stiffness of the failing diabetic heart: importance of fibrosis, advanced glycation end products, and myocyte resting tension. Circulation. 117(1):43-51

34. Agrawal V, Agrawal A, Dwivedi AN, Tripathi K (2016) Correlation between $2 \mathrm{D}$ echocardiography and multidetector row $\mathrm{CT}$ for early detection of diastolic dysfunction in normotensive diabetic patients. J Clin Diagn Res 10(8):OC27-OC30

35. Seferovic-Mitrovic JP, Lalic NM, Vujisic-Tesic B, Lalic K, Jotic A, Ristic AD et al (2011) Asymptomatic cardiovascular manifestations in diabetes mellitus: left ventricular diastolic dysfunction and silent myocardial ischemia. Srp Arh Celok Lek 139(9-10):599-604

36. Aroor AR, Mandavia CH, Sowers JR (2012) Insulin resistance and heart failure: molecular mechanisms. Heart Fail Clin 8(4):609-617

37. Jain S, Nawal C, Singh A, Chejara RS, Barasara S, Marker S (2018) Echocardiographic evaluation of left ventricular diastolic dysfunction in recently diagnosed type 2 diabetes mellitus. Int J Res Med Sci 6(5):16911693

38. Kumar VS, Sreelatha M, Ramesh K, Shekar GC (2017) Study of left ventricular diastolic dysfunction in type 2 diabetes mellitus patients. Int I Sci Study 5(4): 219-224 
39. Suresh G, Alva R, Prakash P, Saya RP (2017) Prevalence of asymptomatic left ventricular diastolic dysfunction in type 2 diabetic patients and healthy controls: a comparative study. Arch Med Health Sci 5(1):30

40. Blomstrand P, Östgren CJ, Nyström FH, Festin K, Engvall M, Lindström T et al (2015) Left ventricular diastolic function, assessed by echocardiography and tissue Doppler imaging, is a strong predictor of cardiovascular events, superior to global left ventricular longitudinal strain, in patients with type 2 diabetes. Eur Heart J Cardiovasc Imaging 16(9):1000-1007

41. From AM, Scott CG, Chen HH (2009) Changes in diastolic dysfunction in diabetes mellitus over time. Am J Cardiol 103(10):1463-1466

42. Cioffi G, Faggiano P, Lucci D, Maggioni AP, Manicardi V, Travaglini A et al (2013) Left ventricular dysfunction and outcome at two-year follow-up in patients with type 2 diabetes: The DYDA study. Diabetes Res Clin Pract 101(2):236-242

43. Schannwell CM, Schneppenheim M, Perings S, Plehn G, Strauer B (2002) Left ventricular diastolic dysfunction as an early manifestation of diabetic cardiomyopathy. Cardiology. 98(1-2):33-39

\section{Publisher's Note}

Springer Nature remains neutral with regard to jurisdictional claims in published maps and institutional affiliations.

\section{Submit your manuscript to a SpringerOpen ${ }^{\circ}$ journal and benefit from:}

- Convenient online submission

- Rigorous peer review

- Open access: articles freely available online

High visibility within the field

- Retaining the copyright to your article

Submit your next manuscript at $\boldsymbol{\nabla}$ springeropen.com 